\title{
STABILITY INDICATING METHOD DEVELOPMENT AND VALIDATION OF METFORMIN AND ERTUGLIFLOZIN BY HIGH-PERFORMANCE LIQUID CHROMATOGRAPHY WITH PDA DETECTION AND ITS APPLICATION TO TABLET DOSAGE FORM
}

\author{
KADALI JAGADEESH ${ }^{1}$, ANNAPURNA N ${ }^{2 *}$ \\ ${ }^{1}$ Department of Basic Science, Shri Vishnu Engineering College for Women, Bhimavaram, Andhra Pradesh, India. ${ }^{2}$ Department of \\ Engineering Chemistry, AU College of Engineering (A), Andhra University, Visakhapatnam, Andhra Pradesh, India. \\ Email: drannapurna.nowduri@gmail.com
}

Received: 03 November 2018, Revised and Accepted: 04 January 2019

ABSTRACT

Objective: A sensitive, rapid, accurate, and precise stability indicating high-performance liquid chromatography method was developed and validated for the simultaneous estimation of metformin (MET) and ertugliflozin (ERT).

Methods: The planned chromatographic method was developed using Kromasil C18 column using 0.1 M sodium dihydrogen phosphate methanol (50:50, by volume, $\mathrm{pH} 4.0$ ) as mobile phase system followed by peak area response measurement at $238 \mathrm{~nm}$. The developed method was validated by means of ICH guidelines about system suitability, linearity, sensitivity, selectivity, accuracy, precision, robustness, and specificity.

Results: Calibration curves of MET and ERT are linear from 250 to $750 \mu \mathrm{g} / \mathrm{ml}$ and 3.75 to $11.25 \mu \mathrm{g} / \mathrm{ml}$, respectively. Relative standard deviation is $<2.0 \%$ and recovery is $100 \%$. Successfully, the developed method was applied for the simultaneous determination of MET and ERT in tablets and to study degradation of MET and ERT in acidic, alkaline, oxidation, thermal, and photolytic degradation conditions. No obstructions from additional common excipients of tablets and degradants were observed.

Conclusion: The results recommended method suitability for the analysis of MET and ERT in quality control laboratories.

Keywords: Antidiabetic agents, Metformin, Ertugliflozin, Degradation, Analysis.

(c) 2019 The Authors. Published by Innovare Academic Sciences Pvt Ltd. This is an open access article under the CC BY license (http://creativecommons. org/licenses/by/4. 0/) DOI: http://dx.doi.org/10.22159/ajpcr.2019.v12i3.30626

\section{INTRODUCTION}

Ertugliflozin (ERT) is a selective inhibitor for sodium needy glucose cotransporters [1]. This cotransporter is responsible for reabsorption of glucose from glomerulus. ERT is prescribed for patients (adults) with Type II diabetes for controlling blood glucose level [2,3]. ERT belongs to gliflozins class of drug and is chemically described as $(1 S, 2 S, 3 S, 4 R$, 5S)-5-[4-Chloro-3-(4-ethoxybenzyl)phenyl]-1-(hydroxymethyl)-6,8dioxabicyclo[3.2.1]octane-2,3,4-triol (Fig. 1).

Metformin (MET) is an antihyperglycemic drug which belongs to the biguanide category [4]. MET is an approved medication prescribed for the treatment of Type II diabetes. MET controls blood glucose level by decreasing hepatic production of glucose, decreasing gastrointestinal absorption of glucose, and increasing target cell sensitivity to insulin [5-7]. Chemically, MET is described as $\mathrm{N}, \mathrm{N}$ dimethylimidodicarbonimidic diamide (Fig. 1).

A fixed combination of ERT and MET was approved by FDA to control blood glucose level in Type II diabetic patients [8,9]. ERT and MET combination is used in addition to exercise and diet. ERT and MET combination is used for diabetic patients who are not satisfactorily controlled with a dosage containing ERT or MET alone.

A detailed survey for literature on ERT and MET combination reveals that no reported high-performance liquid chromatography (RPHPLC) method for the assay of two drugs in combination. The current investigation aims at developing and validating rapid, simple, sensitive, accurate, and reproducible stability indicating RP-HPLC method to determine the concentration of ERT and MET for the application in tablets.

\section{METHODS}

Chemicals and materials

ERT and MET reference standard drugs were supplied by Lara drugs Pvt. Ltd., Hyderabad, India, and Rainbow Pharma Training Labs, Hyderabad, India. Segluromet ${ }^{\mathrm{TM}}$ (ERT $7.5 \mathrm{mg}$ and MET $500 \mathrm{mg}$ ) tablets by Merck and Co., Inc., USA. Hydrogen peroxide, orthophosphoric acid, sodium dihydrogen phosphate, hydrochloric acid, and sodium hydroxide were purchased from Sd. Fine Chemicals Ltd., Mumbai, India. Methanol was purchased from Merck India Ltd., Mumbai, India. Water was acquired from a Milli-Q water system (Millipore, USA). For filtration of samples and mobile phase, $0.45 \mu \mathrm{m}$ membrane filter was used.

\section{Instruments and HPLC conditions}

A waters alliance HPLC system (2695 module) coupled with photodiode array detector and equipped with an autosampler, degasser and column oven were used for the analysis. Empower 2 software was employed for data acquisition. Separation was performed using a Kromasil C18 column $(250 \mathrm{~mm} \times 4.6 \mathrm{~mm})$ with a particle size of $5.0 \mu \mathrm{m}$. The mobile phase consisting of $0.1 \mathrm{M}$ sodium dihydrogen phosphate:methanol $(50: 50 \mathrm{v} / \mathrm{v}, \mathrm{pH} 4.0)$ was delivered at $1.0 \mathrm{ml} /$ minutes flow rate. Injection volume was $10 \mu \mathrm{l}$; detection wavelength was set at 238 and a total run time of $8 \mathrm{~min}$. For quantification, the peak area response of ERT and MET was compared with corresponding calibration curves, wherein the peak area response of the calibration standards was plotted against their concentrations.

Preparation of stock and calibration standard solutions ERT and MET stock solution was prepared in diluent (mobile phase) at a concentration of $5000 \mu \mathrm{g} / \mathrm{ml}$ (ERT) and $75 \mu \mathrm{g} / \mathrm{ml}$ (MET). Till its use, the stock solution was stored at $4^{\circ} \mathrm{C}$. The calibration standard 
solutions were made by successive dilution of the stock solution at the concentration ranges of $250-750 \mu \mathrm{g} / \mathrm{ml}$ and $3.75-11.25 \mu \mathrm{g} / \mathrm{ml}$ for ERT and MET, respectively.

\section{Calibration graph}

Five calibration solutions in the concentration range $250-750 \mu \mathrm{g} / \mathrm{ml}$ (MET) and 3.75-11.25 $\mu \mathrm{g} / \mathrm{ml}$ (ERT and MET) were analyzed by the proposed method. For quantification, the peak area response of ERT and MET was compared with corresponding calibration curves, wherein the peak area response of the calibration standards was plotted against their concentrations. The intercepts and slopes of the calibration lines were also determined.

\section{Assay of ERT and MET in combined tablet form}

Ten tablets were weighed and powdered. Tablet powder corresponding to $500 \mathrm{mg}$ of MET and $7.5 \mathrm{mg}$ of ERT was transferred into $100 \mathrm{ml}$ flask. $30 \mathrm{~mL}$ of mobile phase was added and then mixed. The solution was sonicated for $15 \mathrm{~min}$ and diluted to mark with mobile phase. The resultant solution was filtered using a $0.45 \mu \mathrm{m}$ membrane filter and was appropriately diluted to get the test sample solution having $7.5 \mu \mathrm{g} / \mathrm{ml}$ (ERT) and $500 \mu \mathrm{g} / \mathrm{ml}$ (MET). Test sample solution $(10 \mu \mathrm{l})$ was injected into the system and was analyzed using described HPLC conditions. The assay was repeated 3 times. The peak areas of ERT and MET were measured. The percentage of ERT and MET was calculated using a regression equation which was derived from the corresponding calibration curve.

\section{Forced degradation studies}

This was done by the following guidelines of an international conference on harmonization [10].

\section{Acidic hydrolysis}

An aliquot (10 ml) of tablet sample stock solution $(75 \mu \mathrm{g} / \mathrm{ml}$ of ERT and $5000 \mu \mathrm{g} / \mathrm{ml}$ of MET) was transferred into $100 \mathrm{ml}$ each volumetric flask, and then $10 \mathrm{ml}$ of $0.1 \mathrm{~N} \mathrm{HCl}$ was added. The contents of the flask were sonicated at room temperature for $30 \mathrm{~min}$. Then, the flasks were cooled to room temperature, neutralized (by adding $0.1 \mathrm{~N} \mathrm{NaOH}$ ) and diluted to $100 \mathrm{ml}$ with mobile phase. Further, dilution with mobile phase was done to get $7.5 \mu \mathrm{g} / \mathrm{ml}$ for ERT and $500 \mu \mathrm{g} / \mathrm{ml}$ for MET. After filtration through $0.45 \mu \mathrm{m}$ membrane filter, an aliquot $(10 \mu \mathrm{l})$ from the solution was injected into the HPLC system. The proposed assay procedure is explained here.

\section{Alkaline hydrolysis}

An aliquot $(10 \mathrm{ml})$ of tablet sample stock solution $(75 \mu \mathrm{g} / \mathrm{ml}$ of ERT and $5000 \mu \mathrm{g} / \mathrm{ml}$ of MET) was transferred into $100 \mathrm{ml}$ volumetric flasks, then $10 \mathrm{ml}$ of $0.1 \mathrm{~N} \mathrm{NaOH}$ was added. The flask with contents was allowed and sonicated at room temperature for $30 \mathrm{~min}$. After cooling to room temperature, contents of the flasks were neutralized (by adding $0.1 \mathrm{~N} \mathrm{HCl}$ ) and completed with mobile phase till the volume. Later, the solution was diluted with methanol to obtain $7.5 \mu \mathrm{g} / \mathrm{ml}$ for ERT and $500 \mu \mathrm{g} / \mathrm{ml}$ for MET, and then filtered using $0.45 \mu \mathrm{m}$ membrane filter. An aliquot of $10 \mu \mathrm{l}$ from the solution was applied into the HPLC system. The proposed assay procedure is explained here.

\section{Oxidative degradation}

An aliquot $(10 \mathrm{ml})$ of tablet sample stock solution $(75 \mu \mathrm{g} / \mathrm{ml}$ of ERT and $5000 \mu \mathrm{g} / \mathrm{ml}$ of MET) was transferred into $100 \mathrm{ml}$ volumetric flasks, and then $10 \mathrm{ml}$ of $30 \% \mathrm{H}_{2} \mathrm{O}_{2}$ was added. The flask was allowed for sonication at room temperature for $30 \mathrm{~min}$ and completed to $100 \mathrm{ml}$ with mobile phase. To prepare the final concentration, further dilution was made with methanol to a concentration $7.5 \mu \mathrm{g} / \mathrm{ml}$ for ERT and $500 \mu \mathrm{g} / \mathrm{ml}$ for MET. After filtration through $0.45 \mu \mathrm{m}$ membrane filter, $10 \mu \mathrm{l}$ of solution was prepared and was applied into the HPLC system. The proposed assay procedure is explained here.

\section{Thermal hydrolysis}

Accurately weighed quantity of tablet powder corresponding to $500 \mathrm{mg}$ of MET and 7.5 mg of ERT was placed in a Petrie dish. The Petric dish was heated in a hot air oven at $105^{\circ} \mathrm{C}$ for $30 \mathrm{~min}$ and was cooled to room temperature. The procedure is explained in section "Assay of ERT and MET in combined tablet form" is explained here.

\section{Photolysis}

An accurately weighed quantity of tablet powder equal to $500 \mathrm{mg}$ of MET and $7.5 \mathrm{mg}$ of ERT was placed in a Petrie dish. The Petric dish was kept under sunlight for $24 \mathrm{~h}$. The Petric dish was cooled to room temperature, and this procedure is in section "Assay of ERT and MET in combined tablet form" is explained here.

\section{RESULTS AND DISCUSSION}

\section{Method development}

The experimental HPLC variables tested include the type of analytical column (Waters C18, Supelco C18, and Kromasil C18), type of buffer (orthophosphoric acid buffer and sodium dihydrogen phosphate buffer) $\mathrm{pH}$ of buffer $(3,4$, and 5), percentage of methanol (40-60\%), flow rate of mobile phase $(0.8-1.2)$, and column temperature $\left(25^{\circ} \mathrm{C}, 30^{\circ} \mathrm{C}\right.$, and $35^{\circ} \mathrm{C}$ ). The overall chromatographic conditions for the separation of the studied drug peaks with adequate sensitivity, resolution, and peak shape are summarized in Table 1. The chromatogram obtained using optimized HPLC conditions and is presented in Fig. 2.

\section{Method validation}

This was done following guidelines of an international conference on harmonization [11].

\section{System suitability}

This parameter was used to evaluate the reproducibility of the HPLC system for the analysis of ERT and MET. In this method, using five duplicate injections of a standard drug solution containing $7.5 \mu \mathrm{g} / \mathrm{ml}$ of ERT and $500 \mu \mathrm{g} / \mathrm{ml}$ of MET were used. The parameters calculated were peak area, retention time, plate count, resolution, and peak symmetry (Table 2).

\section{Selectivity}

Selectivity of the proposed method was weighed by comparing the chromatograms obtained from the mobile phase blank, placebo blank, and tablet sample $(7.5 \mu \mathrm{g} / \mathrm{ml}$-ERT and $500 \mu \mathrm{g} / \mathrm{ml}$-MET) with the chromatogram obtained from the standard drug solution (7.5 $\mu \mathrm{g} / \mathrm{ml}-\mathrm{ERT}$ and $500 \mu \mathrm{g} / \mathrm{ml}-\mathrm{MET}$ ). The chromatograms of the studied samples are shown in Fig. 3. No interfering peak was observed at the retention time of ERT and MET. Thus, it proved the method's selectivity.

\section{Linearity and sensitivity}

Herein work, linear calibration graphs for MET and ERT were constructed by plotting the peak area of MET and ERT against MET and ERT concentrations. Regression data were summarized in Table 3. Linear regression analysis data of calibration graphs proved to be good linear association between the concentrations of studied drugs and their corresponding peak areas. The method showed linearity over

Table 1: HPLC parameters for the separation and analysis of ERT and MET

\begin{tabular}{ll}
\hline Parameter & Particulars \\
\hline Column & Kromasil C18, 250 $\mathrm{mm} \times 4.6 \mathrm{~mm}$ \\
& i.d., and $5 \mu \mathrm{m}$ particle size \\
Column temperature & $25^{\circ} \mathrm{C}$ \\
Mobile phase & Sodium dihydrogen phosphate $(\mathrm{pH} 4.0 ;$ \\
& $0.1 \mathrm{M}):$ methanol $(50: 50 \mathrm{v} / \mathrm{v})$ \\
Flow rate & $1.0 \mathrm{ml} / \mathrm{min}$ \\
Detection & $238 \mathrm{~nm}$ \\
Injection volume & $10 \mu \mathrm{l}$ \\
Retention time & $\mathrm{MET}-2.481$ min and ERT $-4.140 \mathrm{~min}$ \\
\hline
\end{tabular}

HPLC: High-performance liquid chromatography, MET: Metformin, ERT: Ertugliflozin 
Table 2: Test results for system suitability

\begin{tabular}{|c|c|c|c|c|c|}
\hline \multirow{2}{*}{$\begin{array}{l}\text { Parameters } \\
\text { Drug }\end{array}$} & \multicolumn{2}{|c|}{ Value obtained (mean of 5) } & \multicolumn{2}{|c|}{ RSD (\%) } & \multirow{2}{*}{$\begin{array}{l}\text { Recommended value } \\
-\end{array}$} \\
\hline & MET & ERT & MET & ERT & \\
\hline Retention time of drug (min) & 2.480 & 4.135 & 0.046 & 0.105 & RSD NMT $2 \%$ \\
\hline Peak area of drug (mAU) & 4786137 & 1246433 & 0.062 & 0.057 & RSD NMT $2 \%$ \\
\hline Plate count $(\mathrm{N})$ & 3659 & 7462 & 0.801 & 1.053 & NLT 2000 \\
\hline Tailing factor (T) & 1.428 & 1.523 & 0.313 & 0.293 & NMT 2 \\
\hline Resolution (R) & - & 8.943 & - & 0.551 & NLT \\
\hline
\end{tabular}

RSD: Relative standard deviation, NMT: Not more than, NLT: Not less than, MET: Metformin, ERT: Ertugliflozin

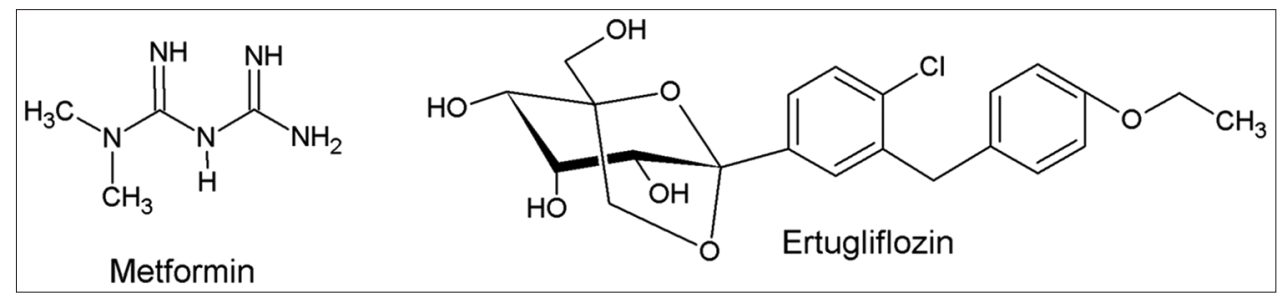

Fig. 1: Structure of metformin and ertugliflozin

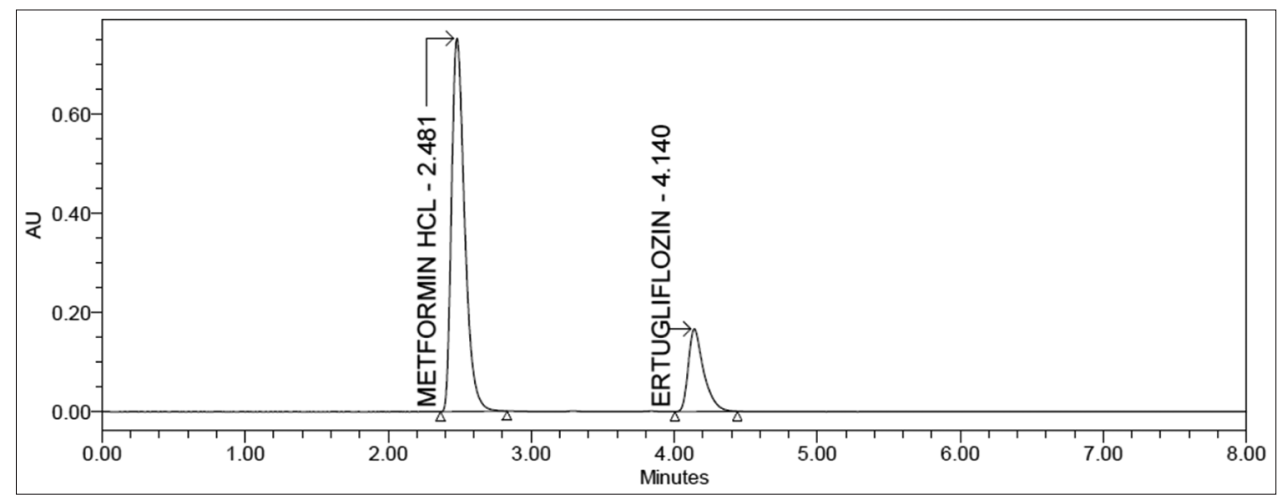

Fig. 2: Ertugliflozin and metformin chromatogram obtained using optimized high-performance liquid chromatography conditions
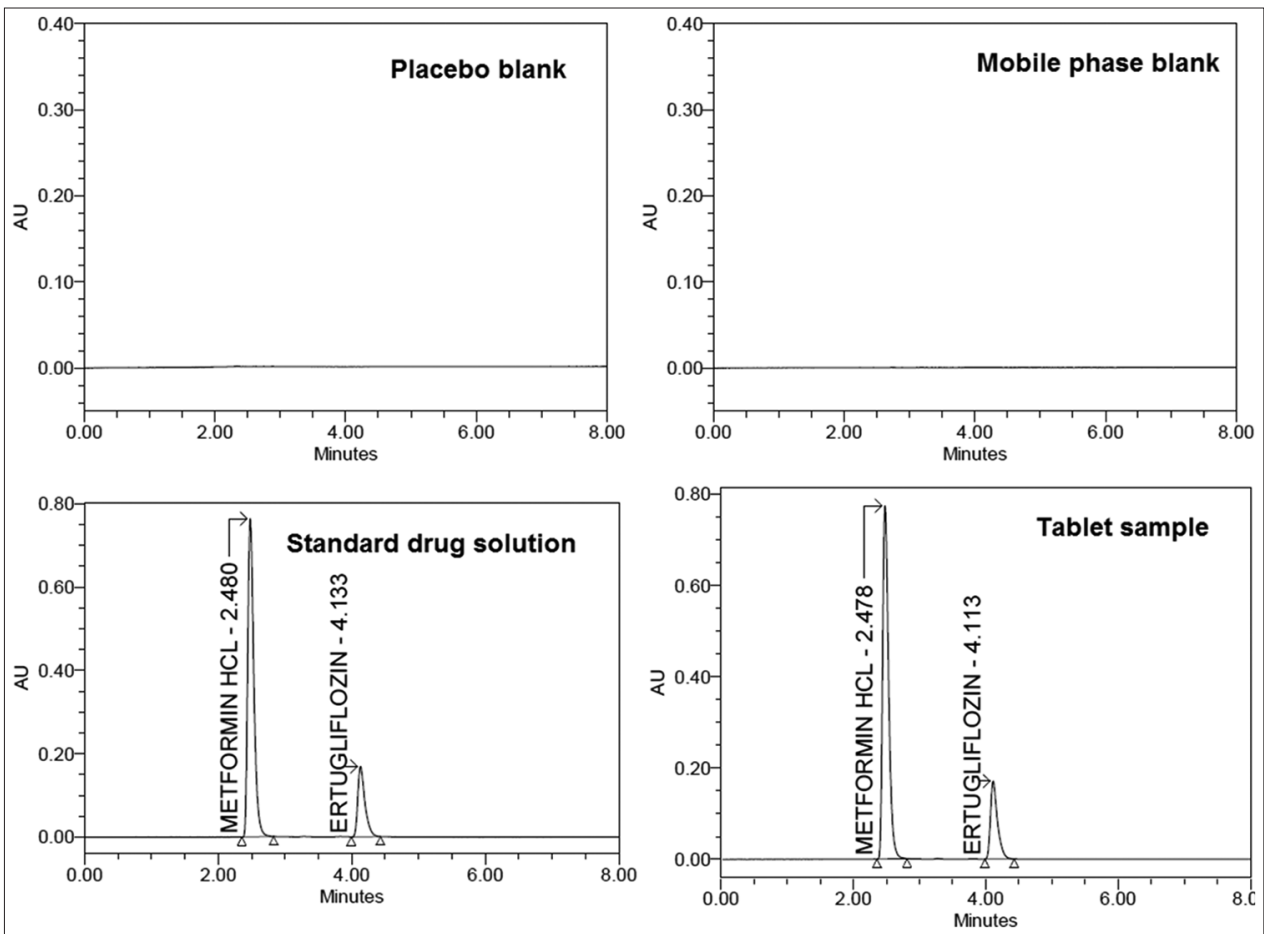

Fig. 3: Selectivity test chromatograms 
the concentration range of $250-750 \mu \mathrm{g} / \mathrm{ml}$ and $3.75-11.25 \mu \mathrm{g} / \mathrm{ml}$ with a regression coefficient of 0.9999 and 0.9997 for MET and ERT, respectively.

Using limit of detection (LOD) and limit of quantitation (LOQ), the sensitivity of the method was assessed. The LOD and LOQ were calculated following ICH guidelines [11] and are presented in Table 3. Results point out good sensitivity of the proposed method.

\section{Precision and accuracy}

Precision and accuracy of standard drug solution $(7.5 \mu \mathrm{g} / \mathrm{ml}-\mathrm{ERT}$ and $500 \mu \mathrm{g} / \mathrm{ml}-\mathrm{MET}$ ) were used to verify the reproducibility of the developed HPLC method. Five replicate measurements were documented. Accuracy and precision were expressed in terms of percentage assay and percentage relative standard deviation, respectively. The values for accuracy and precision are good enough according to the ICH guidelines [11] as shown in Table 4.

\section{Recovery test}

Recovery tests (to further evaluate method accuracy) were carried out by adding standard drug at three different levels $(50 \%, 100 \%$, and $150 \%$ of label claim) to the preanalyzed sample solution $[12,13]$. The solutions were analyzed 3 times at each concentration level, using this method. The concentrations of MET and ERT were calculated from the corresponding calibration curve or regression equation. The results were shown in terms of percent recovery. Results shown in Table 5 represent good accuracy and no interference from the excipients of the tablet dosage form.

\section{Robustness}

In the present work, robustness was checked by determining the result of small changes in the HPLC experimental parameters. The parameters were studied in mobile phase composition, $\mathrm{pH}$ of the mobile phase,

Table 3: Summary of regression data and sensitivity for MET and ERT

\begin{tabular}{lll}
\hline Parameters & \multicolumn{2}{l}{ Value obtained } \\
\hline $\begin{array}{l}\text { Drug } \\
\text { Linearity }(\mu \mathrm{g} / \mathrm{ml})\end{array}$ & $\begin{array}{l}\text { MET } \\
\text { Regression }\end{array}$ & ERT \\
equation & PA=9559.784 x+4652.2 & PA=164851.84 x+6929.4 \\
$\begin{array}{l}\text { Regression } \\
\text { coefficient }\left(\mathrm{R}^{2}\right)\end{array}$ & 0.9999 & 0.9997 \\
LOD $(\mu \mathrm{g} / \mathrm{ml})$ & 0.563 & \\
LOQ $(\mu \mathrm{g} / \mathrm{ml})$ & 1.878 & 0.038 \\
\hline
\end{tabular}

PA: Peak area of drug, $x$ : Concentration of drug, MET: Metformin,

ERT: Ertugliflozin, LOD: Limit of detection, LOQ: Limit of quantitation column temperature, flow rate, and detection wavelength. It was observed that small differences in the HPLC experimental conditions did not considerably influence the results. This indicates that the new HPLC method is robust for the analysis of ERT and MET (Table 6).

\section{MET and ERT forced degradation}

Forced degradation testing of MET and ERT was carried out with tablet sample using ICH prescribed stress conditions [10]. Percentage degradation of MET and ERT under stress conditions applied was estimated and listed in Table 7. Degradation results indicate that ERT and MET are degraded more in thermal condition and less in oxidative condition. The retention times of degradants in all the conditions are present in Table 7. As the developed HPLC method could separate MET and ERT from their degradation products effectively, this method can be employed as a stability indicating method (Fig. 4). The MET and ERT peak purity was tested using a PDA detector. For peak purity testing, peak purity angle and peak purity threshold were determined in all the stress conditions. The values are shown in Table 7. MET and ERT peaks remain pure in all stressed samples using HPLC parameters.

\section{Application of the developed HPLC method}

The HPLC method is applied for the determination of MET and ERT in their combined tablet form. The results (Table 8) indicate that the developed HPLC method is suitable for the assay of MET and ERT with good recoveries and low relative standard deviation. There are no interferences from commonly encountered excipients. The results recommend this method for its suitability in the analysis of MET and ERT in quality control laboratories.

\section{CONCLUSION}

Validated stability indicates that the HPLC method was developed for analyzing MET and ERT simultaneously. This method demonstrated a linear range of $250-750 \mu \mathrm{g} / \mathrm{ml}$ and $3.75-11.25 \mu \mathrm{g} / \mathrm{ml}$ for MET and ERT, respectively. Total analyzing time was $<9$ min which proved the quickness of the proposed method. The method is able to quantify MET and ERT in the presence of forced degradation products selectively and specifically, and the result shows that this is stability indicating method. The present method is applied with good accuracy and precision for the quantitation of MET and ERT in tablets. The results recommend the suitability of the method for the analysis of MET and ERT in quality control laboratories.

\section{ACKNOWLEDGMENTS}

Author, Kadali Jagadeesh, would like to thank Dr. G. Srinivasa Rao, Principal, Shri Vishnu Engineering College for Women, Bhimavaram and Dr. T. Sree Rama Murthy, Head, Department of Basic Sciences for providing necessary facilities to carry out the research work.

Table 4: Precision and accuracy of the proposed method

\begin{tabular}{lllll}
\hline Drug & Concentration $(\boldsymbol{\mu g} / \mathbf{m l})$ & Peak area $(\mathbf{m A U}) *$ & Determined $(\boldsymbol{\mu g} / \mathbf{m l}) *^{*}$ Precision $(\% \mathrm{RSD}) * *^{* *}$ Accuracy $(\%$ assay)* \\
\hline MET & 500 & 4784206 & 499.80 & 0.066 \\
ERT & 7.5 & 1244899 & 7.49 & 0.227 \\
\hline
\end{tabular}

*Mean of five determined values; **relative standard deviation for five determined values, MET: Metformin, ERT: Ertugliflozin

Table 5: Recovery analysis of MET and ERT

\begin{tabular}{|c|c|c|c|c|c|}
\hline \multirow[t]{2}{*}{ Drug } & \multirow[t]{2}{*}{ Spiked level } & \multirow[t]{2}{*}{ Labeled claim (mg) } & \multirow[t]{2}{*}{ Spiked (mg) } & \multicolumn{2}{|l|}{ Value obtained } \\
\hline & & & & Recovered (\%)* & $\operatorname{RSD}(\%)^{* *}$ \\
\hline \multirow[t]{3}{*}{ MET } & 50 & 500 & 250 & 99.88 & 0.131 \\
\hline & 100 & 500 & 500 & 99.63 & 0.044 \\
\hline & 150 & 500 & 750 & 99.63 & 0.068 \\
\hline \multirow{2}{*}{ ERT } & 50 & 7.5 & 3.75 & 100.19 & 0.269 \\
\hline & 100 & 7.5 & 7.5 & 100.61 & 0.134 \\
\hline
\end{tabular}

*Mean of three determined values; **relative standard deviation for three determined values, MET: Metformin, ERT: Ertugliflozin 
Table 6: Robustness test data for MET and ERT

\begin{tabular}{|c|c|c|c|c|c|}
\hline Drug & Investigated value & Peak area (mAU) & Plate count $(\mathrm{N})$ & Tailing factor $(\mathrm{T})$ & Resolution (R) \\
\hline \multicolumn{6}{|c|}{ Mobile phase ratio: $0.1 \mathrm{M} \mathrm{NaH2PO4:} \mathrm{Methanol} \mathrm{(50:50} \mathrm{v/v,} \mathrm{optimized} \mathrm{value)}$} \\
\hline \multirow[t]{2}{*}{ MET } & $45: 55$ & $4,771,165$ & 3601 & 1.30 & - \\
\hline & $55: 45$ & $4,792,696$ & 3802 & 1.33 & - \\
\hline \multirow[t]{2}{*}{ ERT } & $45: 55$ & $1,233,252$ & 6930 & 1.42 & 8.65 \\
\hline & $55: 45$ & $1,250,643$ & 7201 & 1.45 & 8.81 \\
\hline \multicolumn{6}{|c|}{ Mobile phase $\mathrm{pH}(4.0$, optimized value $)$} \\
\hline MET & 3.8 & $4,782,428$ & 3663 & 1.41 & - \\
\hline \multirow[t]{2}{*}{ ERT } & 3.8 & $1,249,118$ & 7350 & 1.54 & 8.90 \\
\hline & 4.2 & $1,254,448$ & 7090 & 1.53 & 8.77 \\
\hline \multicolumn{6}{|c|}{ Flow rate of mobile phase $(1.0 \mathrm{ml} / \mathrm{min}$, optimized value $)$} \\
\hline \multirow[t]{2}{*}{ MET } & 0.9 & $4,599,242$ & 3537 & 1.30 & - \\
\hline & 1.1 & $4,651,165$ & 3601 & 1.30 & - \\
\hline \multirow[t]{2}{*}{ ERT } & 0.9 & $1,133,995$ & 6559 & 1.39 & 8.53 \\
\hline & 1.1 & $1,193,252$ & 6930 & 1.42 & 8.65 \\
\hline \multicolumn{6}{|c|}{ Column temperature $\left(25^{\circ} \mathrm{C}\right.$, optimized value $)$} \\
\hline MET & 27 & $4,984,191$ & 3932 & 1.33 & - \\
\hline \multirow[t]{2}{*}{ ERT } & 23 & $1,310,643$ & 7201 & 1.45 & 8.81 \\
\hline & 27 & $1,360,361$ & 7557 & 1.50 & 9.05 \\
\hline \multicolumn{6}{|c|}{ Detection wavelength (238 nm, optimized value) } \\
\hline \multirow[t]{2}{*}{ MET } & 236 & $5,240,786$ & 3711 & 1.43 & - \\
\hline & 240 & $4,438,450$ & 3659 & 1.42 & - \\
\hline \multirow[t]{2}{*}{ ERT } & 236 & $1,109,055$ & 7557 & 1.53 & 8.98 \\
\hline & 240 & $1,484,548$ & 7559 & 1.53 & 8.99 \\
\hline
\end{tabular}

MET: Metformin, ERT: Ertugliflozin
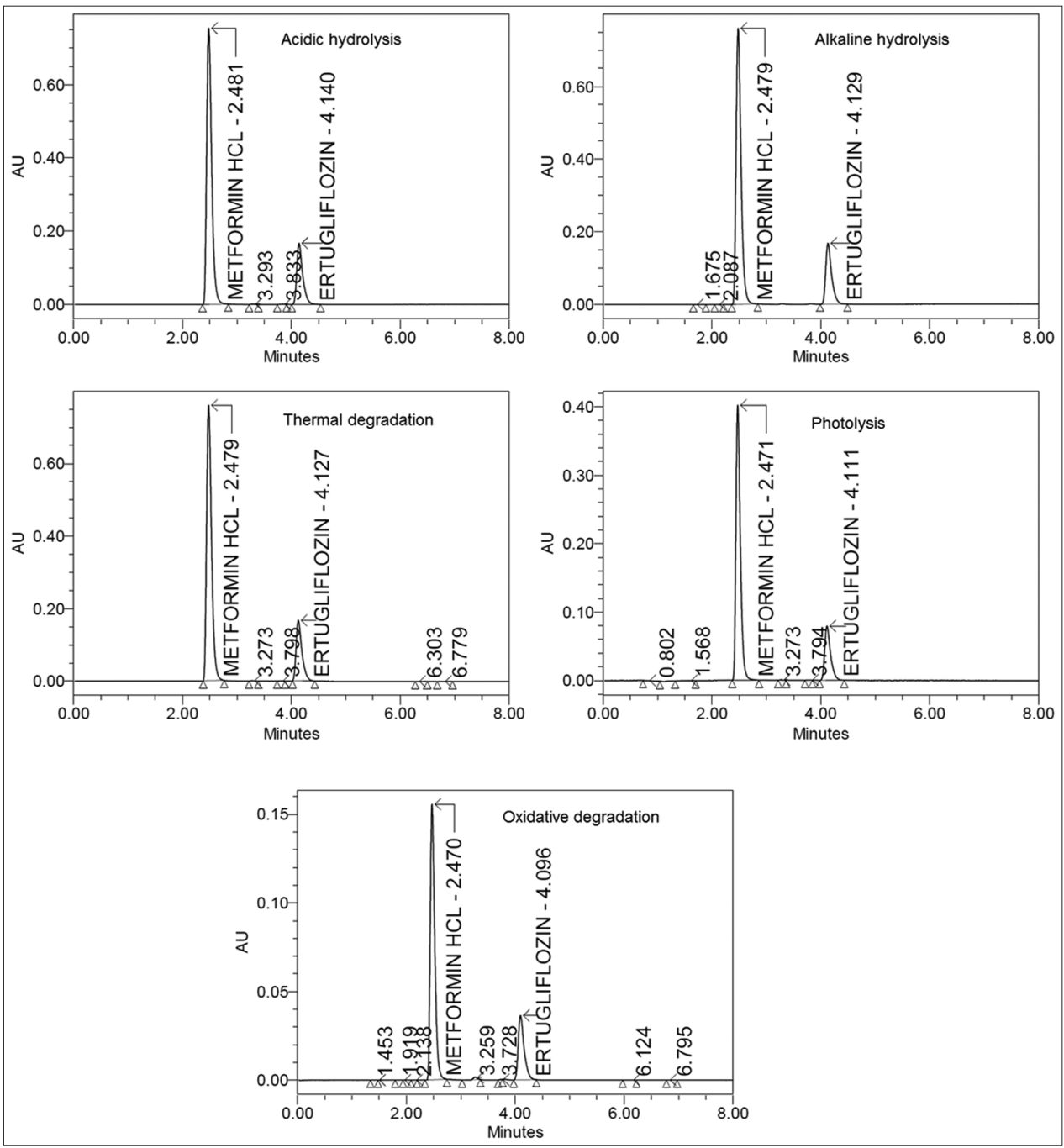

Fig. 4: Chromatograms of metformin and ertugliflozin after degradation 
Table 7: Forced degradation and peak purity test results of MET and ERT

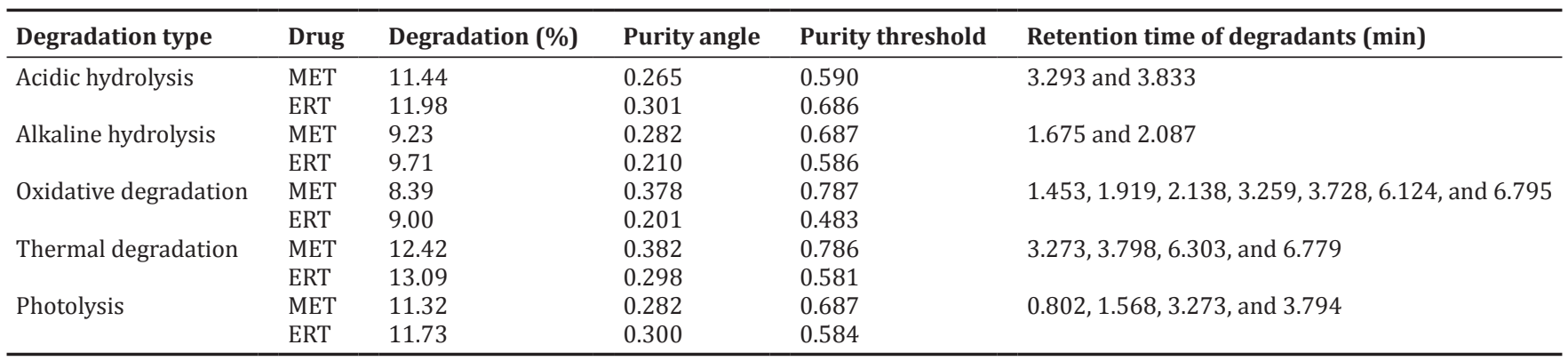

MET: Metformin, ERT: Ertugliflozin

Table 8: Quantification of MET and ERT by the proposed HPLC method

\begin{tabular}{lll}
\hline Parameters & Drug & \\
\cline { 2 - 3 } & MET & ERT \\
\hline Labeled claim (mg) & 500 & 7.50 \\
Obtained value (mg) & 498.20 & 7.53 \\
Recovery (\%)* & 99.64 & 100.46 \\
RSD (\%)** & 0.080 & 0.081 \\
\hline
\end{tabular}

*Mean of three determined values; ${ }^{* *}$ relative standard deviation for 3

determined values, MET: Metformin, ERT: Ertugliflozin

\section{AUTHOR'S CONTRIBUTIONS}

$\mathrm{KJ}$ has done this investigation work under the guidance of Dr. NA.

\section{CONFLICTS OF INTEREST}

Authors declare that none of the conflicts of interest present in this investigation.

\section{REFERENCES}

1. Marlene B. FDA Approves SGLT2 Inhibitor Ertugliflozin for Type 2 Diabetes. Medscape; 2017. Available from: https://www.medscape. com/viewarticle/890446.

2. From the medical letter on drugs and therapeutics. Ertugliflozin for Type 2 diabetes. JAMA 2018;319:2434-35.

3. Cinti F, Moffa S, Impronta F, Cefalo CM, Sun VA, Sorice GP, et al. Spotlight on ertugliflozin and its potential in the treatment of Type 2 diabetes: Evidence to date. Drug Des Devel Ther 2017;11:2905-19.

4. Wang YW, He SJ, Feng X, Cheng J, Luo YT, Tian L, et al. Metformin: A review of its potential indications. Drug Des Devel Ther 2017;11:2421-9.

5. Rena G, Hardie DG, Pearson ER. The mechanisms of action of metformin. Diabetologia 2017;60:1577-85.

6. Madiraju AK, Qiu Y, Perry RJ, Rahimi Y, Zhang XM, Zhang D, et al. Metformin inhibits gluconeogenesis via a redox-dependent mechanism in vivo. Nat Med 2018;24:1384-94.

7. Madiraju AK, Erion DM, Rahimi Y, Zhang XM, Braddock DT, Albright RA, et al. Metformin suppresses gluconeogenesis by inhibiting mitochondrial glycerophosphate dehydrogenase. Nature 2014;510:542-6.

8. FDA Approves Segluromet. Available from: https://www.drugs. com/newdrugs/fda-approves-segluromet-ertugliflozin-metforminhydrochloride-type-2-diabetes-4669.html.

9. Ertugliflozin/Metformin (By Mouth). PubMed Health, 2018. Available from: https://www.ncbi.nlm.nih.gov/pubmedhealth/ PMHT0031142/?report=details.

10. International Conference on Harmonization (ICH) of Technical Requirements for the Registration of Pharmaceutical for Human Use Stability Testing of New Drugs Substance and Products. Geneva, Switzerland: Q1A (R2); 2003.

11. International Conference on Harmonization; Validation of Analytical Procedures: Text and Methodology, Q2 (R1). Geneva, Switzerland: IFPMA; 2005

12. Hemant KJ, Umakant SJ. Development and validation of RP-HPLC method for estimation of darunavir ethanolate in bulk and tablets. Int $\mathrm{J}$ Pharm Pharm Sci 2015;7:386-9.

13. Babu GR, Rao AL, Rao JV. A rapid RP-HPLC method development and validation for the quantitative estimation ribavirin in tablets. Int $\mathrm{J}$ Pharm Pharm Sci 2015;7:60-3. 